\title{
Intracellular Signaling Process
}

National Cancer Institute

\section{Source}

National Cancer Institute. Intracellular Signaling Process. NCI Thesaurus. Code C21040.

Any subcellular process that is initated by a chemical or mechanical stimulus and results in a specific cellular response. 